\title{
Differential Roles for L-Type Calcium Channel Subtypes in Alcohol Dependence
}

\begin{abstract}
Stefanie Uhrig', David Vandael ${ }^{2}$, Andrea Marcantoni ${ }^{2}$, Nina Dedic ${ }^{3}$, Ainhoa Bilbao', Miriam A Vogt ${ }^{4}$, Natalie Hirth', Laura Broccoli', Rick E Bernardi', Kai Schönig ${ }^{5}$, Peter Gass', Dusan Bartsch ${ }^{5}$, Rainer Spanagel', Jan M Deussing ${ }^{3}$, Wolfgang H Sommer ${ }^{1,6}$, Emilio Carbone ${ }^{2}$ and Anita C Hansson*,

IInstitute of Psychopharmacology, Central Institute of Mental Health, Medical Faculty Mannheim, University of Heidelberg, Mannheim, Germany; ${ }^{2}$ Department of Drug Science, Laboratory of Cellular and Molecular Neuroscience, NIS Center, CNISM, University of Torino, Torino, Italy;

${ }^{3}$ Department of Stress Neurobiology and Neurogenetics, Max Planck Institute of Psychiatry, Munich, Germany; ${ }^{4}$ Department of Psychiatry and Psychotherapy, Central Institute of Mental Health, Medical Faculty Mannheim, University of Heidelberg, Mannheim, Germany; ${ }^{5}$ Department of Molecular Biology, Central Institute of Mental Health, Medical Faculty Mannheim, University of Heidelberg, Mannheim, Germany; ${ }^{6}$ Department of Addictive Behavior and Addiction Medicine, Central Institute for Mental Health, Medical Faculty Mannheim, University of Heidelberg, Mannheim, Germany
\end{abstract}

It has previously been shown that the inhibition of L-type calcium channels (LTCCS) decreases alcohol consumption, although the contribution of the central LTCC subtypes Cavl.2 and Cavl.3 remains unknown. Here, we determined changes in Cavl.2 (Cacnalc) and Cavl.3 (Cacnald) mRNA and protein expression in alcohol-dependent rats during protracted abstinence and naive controls using in situ hybridization and western blot analysis. Functional validation was obtained by electrophysiological recordings of calcium currents in dissociated hippocampal pyramidal neurons. We then measured alcohol self-administration and cue-induced reinstatement of alcohol seeking in dependent and nondependent rats after intracerebroventricular (i.c.v.) injection of the LTCC antagonist verapamil, as well as in mice with an inducible knockout (KO) of Cavl.2 in $\mathrm{Ca}^{2+} /$ calmodulin-dependent protein kinase $\| \alpha$ (CaMKll $\alpha$ )-expressing neurons. Our results show that Cacna I c mRNA concentration was increased in the amygdala and hippocampus of alcohol-dependent rats after 21 days of abstinence, with no changes in Cacnald mRNA. This was associated with increased Cavl.2 protein concentration and L-type calcium current amplitudes. Further analysis of Cacnalc mRNA in the CAI, basolateral amygdala (BLA), and central amygdala (CeA) revealed a dynamic regulation over time during the development of alcohol dependence. The inhibition of central LTCCs via i.c.v. administration of verapamil prevented cue-induced reinstatement of alcohol seeking in alcohol-dependent rats. Further studies in conditional Cavl.2-KO mice showed a lack of dependence-induced increase of alcohol-seeking behavior. Together, our data indicate that central Cavl.2 channels, rather than Cavl.3, mediate alcohol-seeking behavior. This finding may be of interest for the development of new antirelapse medications. Neuropsychopharmacology (2017) 42, 1058-1069; doi:I0.1038/npp.2016.266; published online 4 January 2017

\section{INTRODUCTION}

Although alcohol consumption is widely socially accepted and legal, excessive and compulsive alcohol use has serious consequences for the health, social environment, and ability to work of the individual. The World Health Organization estimates that in 2012, $~ 5.9 \%$ of all global deaths were directly or indirectly attributable to alcohol consumption (World Health Organization, 2014). A large proportion of alcohol-related harm is because of alcohol use disorders (AUD), including addiction. One major concern is relapse that can occur even after years of abstinence, as the repeated

*Correspondence: Dr AC Hansson, Institute of Psychopharmacology, Central Institute for Mental Health, Medical Faculty Mannheim, University of Heidelberg, Square J5, Mannheim D-68159, Germany, Tel: +49 621 1703 6293, Fax: +49 62। 1703 6255,

E-mail: anita.hansson@zi-mannheim.de

Received 19 June 2016; revised 24 November 2016; accepted 25 November 2016; accepted article preview online I December 2016 cycles of alcohol use and abstinence lead to persistent alterations in neurotransmitter systems and brain activity. After withdrawal symptoms have ceased, relapse can be triggered by internal and external factors such as stress or environmental cues (Spanagel, 2009; Heilig et al, 2010). Studying the alterations in the brain underlying the increased propensity to relapse after dependence has developed is therefore of great importance for the development of new and improved therapeutic approaches.

Recently, variation at the CACNA1C gene locus was identified as an important contributor to the risk for psychiatric disorders (Strohmaier et al, 2013; Erk et al, 2014) that in turn has sparked renewed interest in the function of L-type calcium channels (LTCCs) in the brain (Berger and Bartsch, 2014). Two subtypes, Cav1.2 and Cav1.3 (with the respective gene loci CACNA1C and CACNA1D), are expressed in the central nervous system (Hell et al, 1993), and both have been implicated in regulating the effects of, and dependence to, alcohol 
(Pucilowski et al, 1989; Littleton et al, 1990; Rezvani and Janowsky, 1990; Fadda et al, 1992; Colombo et al, 1995; De Beun et al, 1996a,b;Gardell et al, 1997, 1999).

Until recently, little effort has been made to distinguish between LTCC subtypes in the investigation of addictive behaviors. This is largely because of the lack of selective pharmacological tools. Many studies on alcohol drinking behavior have used systemic administration of LTCC ligands, affecting LTCCs not only in the brain but also in various other organs, including the heart (Rezvani and Janowsky, 1990; Fadda et al, 1992; De Beun et al, 1996a, b). Substantial side effects were demonstrated in these studies, having been performed at high doses to compensate for the low brain penetrance of most calcium channel blockers. For example, i.p. administration of nifedipine decreases locomotor activity for up to $12 \mathrm{~h}$ (Bernardi et al, 2014), also increasing plasma corticosterone levels (Waltereit et al, 2008), whereas systemic verapamil administration appears to augment stress-induced impairment of memory retrieval (Rashidy-Pour et al, 2009). This effect is of particular importance as alcohol-dependent rats display an increased sensitivity to stress (Sommer et al, 2008). Furthermore, previous studies on the role of LTCCs have primarily used free choice paradigms in which alcohol was presented as an alternative drinking solution to laboratory rodents that typically does not result in clinically relevant brain alcohol exposure levels or neuroadaptive processes important for the development of addiction.

In this study we examined whether the central LTCC subtypes Cav1.2 and Cav1.3 play different roles in alcohol dependence. We used an established animal model in which dependence is induced by chronic intermittent intoxication with alcohol vapor, leading to persistent neuronal and behavioral adaptations (Rimondini et al, 2002; Meinhardt and Sommer, 2015). Although this postdependent state is based on experimenter controlled intoxication, it has been invaluable in identifying the mechanisms underlying high relapse propensity in addicted subjects, such as chronic hyperactivity of central stress systems, a hyperdopaminergic state during protracted abstinence, and long-lasting alterations of forebrain neurogenesis (Sommer et al, 2008; Hansson et al, 2010; Hirth et al, 2016). Here, we used this model to investigate mRNA and protein expression of LTCC subtypes in several brain regions over the course of intoxication, acute withdrawal, and into protracted abstinence. Functional validation of these findings was obtained using patch-clamp recordings of LTCC currents in CA1 hippocampal neurons. We then tested the effect of central verapamil injection on alcohol self-administration and seeking behavior in alcohol-dependent and nondependent rats. Finally, using transgenic mice with a time- and celltype-specific Cav1.2 knockout (KO), we established the role of Cav1.2 in cue-induced reinstatement of alcohol seeking.

\section{MATERIALS AND METHODS}

Male Wistar rats weighing 210-300 g at the beginning of the experiment were used. Alcohol dependence was induced by exposure to chronic intermittent cycles of alcohol inhalation, as previously described (Rimondini et al, 2002; Sommer et al, 2008; Bjork et al, 2010; Hansson et al, 2010; Meinhardt et al,
2013; Hirth et al, 2016). After 7 weeks of alcohol exposure, rats were killed for Cacna1c and Cacnald mRNA analysis by in situ hybridization at different time points of abstinence $(0,1,3,7$, and 21 days after the last vapor exposure) according to Hansson et al (2010) and Hermann et al (2012). Further analysis on protein and functional level were performed in 3-week abstinent rats by western blotting and electrophysiological patch-clamp recordings of LTCC currents in dissociated hippocampal pyramidal neurons, respectively. In addition, behavioral analyses (alcohol selfadministration and cue-induced reinstatement to alcoholseeking behavior after intracerebroventricular (i.c.v.) injection of verapamil or vehicle (artificial cerebral spinal fluid $(\mathrm{aCSF}))$ were performed in 3-week abstinent rats. Alcohol self-administration and cue-induced reinstatement to alcohol seeking was also analyzed in mice with a conditional knockout of Cav1.2 in $\mathrm{Ca}^{2+} /$ Calmodulin-dependent protein kinase II $\alpha$ (CaMKII $\alpha$ )-expressing cells (Cav1.2 ${ }^{\mathrm{KO}}$, with Cav1.2 $2^{\mathrm{fl} / \mathrm{fl}}$ mice as controls) to establish the role of this LTCC subtype in dependence. All drugs, experimental procedures, stereotactic surgeries, and statistics are described in detail in Supplementary Information. The experiments were conducted in accordance with the ethical guidelines for the care and use of laboratory animals, and were approved by the local animal care committee (Regierungspräsidium Karlsruhe, Germany, license numbers 35-9185.81/G-163/13 and 35-9185.81/G-301/14).

\section{RESULTS}

\section{Cacnalc mRNA and Protein Is Increased in Alcohol- Dependent Rats after 3 Weeks of Abstinence}

Alcohol dependence was induced in rats by exposure to intermittent cycles of alcohol vapor intoxication. Average blood alcohol concentrations per daily cycle were $266.2 \pm 12.6 \mathrm{mg} / \mathrm{dl}$. Transcriptional levels of Cacna1c and Cacnald were measured after 3 weeks of abstinence to investigate long-term changes in mRNA expression in different reward-related forebrain regions (Noori et al, 2012): prefrontal cortex (PFC) (cingulate cortex (Cing), prelimbic cortex (PreL), infralimbic region (IL), and orbitofrontal cortex (OFC)), motor cortex M1, nucleus accumbens (core (AcbC) and shell (AcbS)), caudate putamen $(\mathrm{CPu})$, extended amygdala (bed nucleus of the stria terminalis (BNST), central amygdala (CeA), medial amygdala (MeA), and basolateral amygdala (BLA)), hypothalamic paraventricular nucleus (PVN), and dorsal hippocampal formation (dentate gyrus (DG) and cornus ammon (CA) regions CA1 and CA3) (see Figure $1 \mathrm{a}$ and $\mathrm{b}$ and Table 1).

Cacnalc mRNA was significantly increased in the hippocampus (CA1: 76\%, CA3: 24\%, and CA4: 33\% increase) and amygdala (CeA: $40 \%$, and BLA: $70 \%$ increase, Figure 1a). Cacnalc expression in other analyzed regions remained unchanged. Cacnald mRNA was unchanged in all investigated regions. For absolute values and statistical values, see Table 1.

The increase in Cacnalc expression in the hippocampus was confirmed on the protein level by western blot analysis (Figure 1c). Alcohol-dependent rats showed a $26 \%$ increase of Cav1.2 protein compared with nondependent controls $(p<0.05)$. 

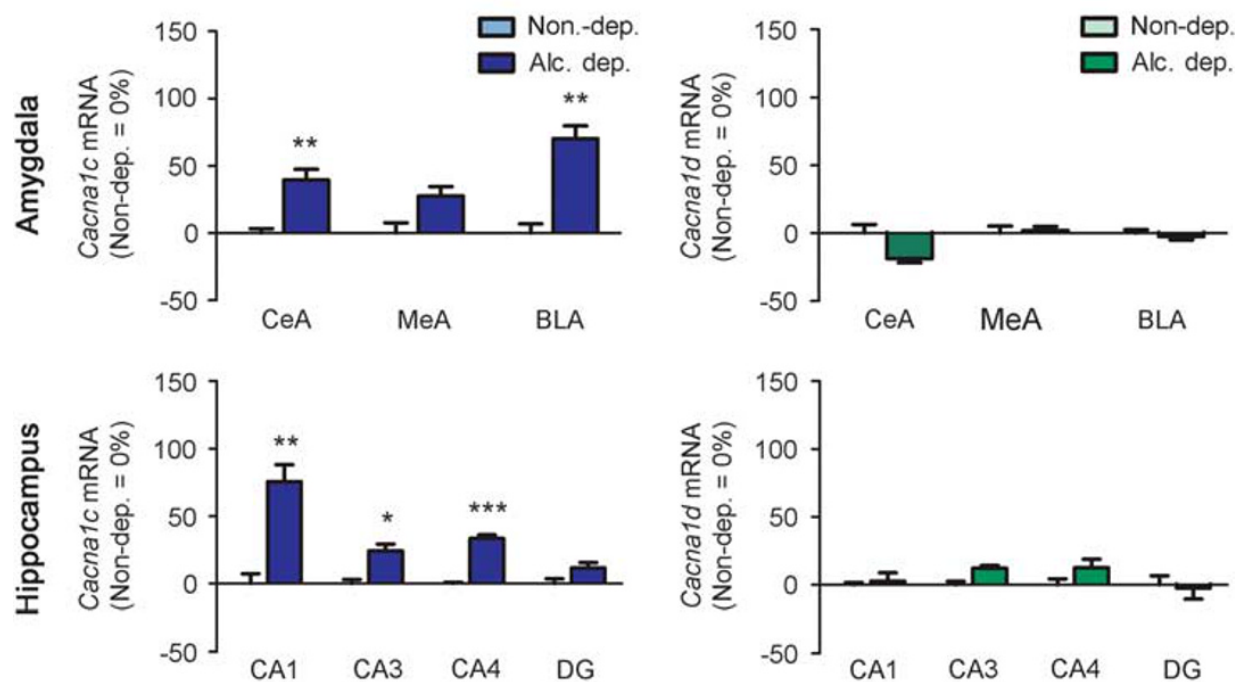

b
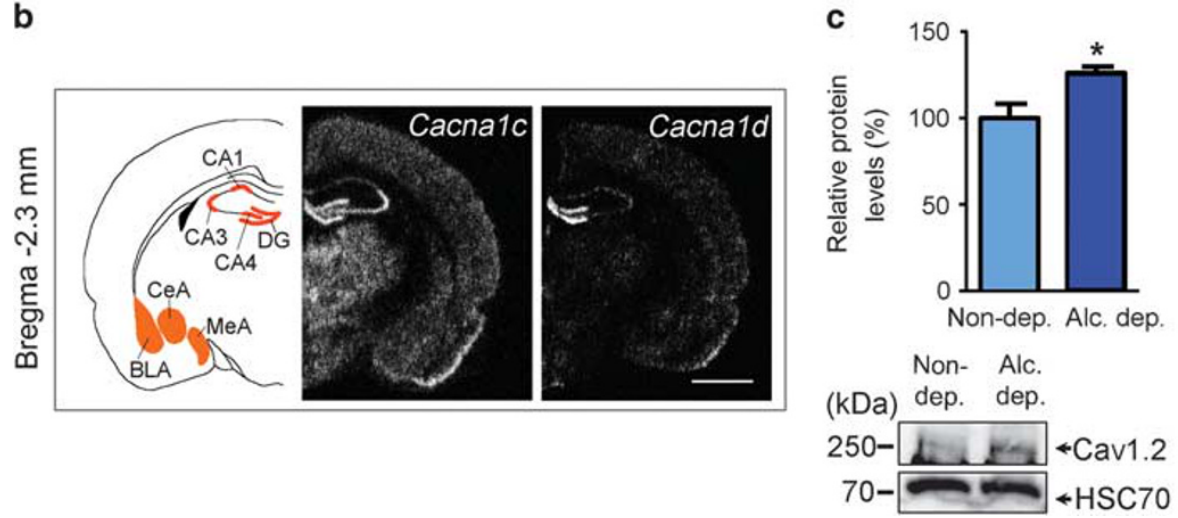

Figure I Cacnalc mRNA and protein are upregulated in alcohol-dependent rats. (a) Changes of Cacnalc and Cacnald mRNA expression in alcoholdependent rats measured by in situ hybridization. Bar graphs show values relative to control rats (Control $=0 \%$ regulation) and are expressed as mean \pm SEM. Statistical analysis was performed by region-wise one-way ANOVA followed by Bonferroni's correction, $n=5-7 / g r o u p$ (detailed in Table I), corrected $p$ values: $* 0.05, * * p<0.0 \mathrm{I}, *^{*} * * 0.00 \mathrm{I}$, alcohol dependent (Alc. dep.). Absolute values of all measured regions are listed in Table I. ISH, in situ hybridization. (b) Schematic representation of measured areas and mRNA expression pattern of Cacnalc and Cacnald at Bregma - $0.3 \mathrm{~mm}$ and $-2.3 \mathrm{~mm}$. Scale bar $=2.5 \mathrm{~mm}$. Central amygdala (CeA), medial amygdala (MeA), and basolateral amygdala (BLA), and dorsal hippocampal formation (dentate gyrus (DG) and cornus ammon (CA) regions CAI and CA3). (c) Western blot analysis of micro-punches from the hippocampal CAI region revealed increased CavI.2 protein levels in alcohol-dependent rats compared with controls. Bar graphs are expressed as mean \pm SEM. Statistical analysis was performed by Student's t-test, $n=8 /$ group, $p$-values: $* 0<0.05$. Representative western blot is shown on the bottom. Alc., alcohol; Alc. dep., alcohol dependent; Non-dep., nondependent.

\section{Dynamic Changes of Cacnalc mRNA during Acute Alcohol Intoxication, Withdrawal, and Extended Abstinence}

Cacnalc mRNA concentration was investigated over time, from acute intoxication to withdrawal and following extended abstinence, in the CA1, CeA, and BLA (Figure 2 and Table 2). Rats were killed immediately after vapor exposure, and after 1, 3, 7, or 21 days of abstinence (Hansson et al, 2010; Hermann et al, 2012). We found highly significant effects of Treatment (CA1: $\mathrm{F}(1,75)=49.48$, $p<0.001 ; \quad$ CeA: $\quad \mathrm{F}(1,73)=137.4, \quad p<0.001 ; \quad$ BLA: $\quad \mathrm{F}$ $(1,77)=46.94, \quad p<0.001)$, Time $(\mathrm{CA} 1: \mathrm{F}(5,75)=13.46$, $p<0.001 ; \quad$ CeA: $\quad \mathrm{F}(5,73)=43.3, \quad p<0.001 ; \quad$ BLA: $\quad \mathrm{F}$ $(5,77)=19.29, p<0.001)$, and a significant interaction of Treatment $\times$ Time (CA1: $F(5,75)=13.46, p<0.001$; CeA: $F$ $(5,73)=43.3, p<0.001$; BLA: $\mathrm{F}(5,77)=19.29, p<0.001)$.
In the CA1, Cacnalc mRNA expression was increased compared with controls when the animals were still intoxicated (0 days; $p<0.05)$. After 1 day, there was a decrease that did not reach significance. Transcriptional levels returned to control levels on day 3 ( $p=$ not significant (n.s.)) before increasing slightly, but not significantly, on day 7. We also found a strong increase in Cacnalc mRNA in alcohol-dependent rats after 21 days of abstinence $(p<0.001)$. In the amygdala, we observed a similar dynamic. On day 0, Cacnalc mRNA was strongly increased (CeA: $p<0.001$; BLA: $p<0.001$ ), on day 1 decreased (CeA: $p<0.01$; BLA: $p<0.01)$, and on day 3 it normalized again (CeA: $p=n$. s.; BLA: $p=$ n.s.). In the CeA, there was a trend toward an increase in Cacnalc mRNA on day $7(p=0.06)$, and a significant increase on day $21 \quad(p<0.001)$. There was no difference between alcohol-dependent and control rats on 
Table I Cacnalc and Cacnald mRNA Expression in Alcohol-Dependent and Nondependent Rats after 3 Weeks of Abstinence

\begin{tabular}{|c|c|c|c|c|c|c|c|}
\hline mRNA & Region & Non-dep. (nCi/g) & Alc. dep. (nCi/g) & $\mathbf{F}$ & $P$ & N Non-dep. & N Alc. dep. \\
\hline \multirow[t]{12}{*}{ Cacnalc } & Cing & $2.01 \pm 0.3$ & $1.96 \pm 0.1$ & 0.03 & n.s. & 5 & 7 \\
\hline & PreL & $2.77 \pm 0.3$ & $3.54 \pm 0.2$ & 4.15 & n.s. & 6 & 7 \\
\hline & $\|$ & $4.4 I \pm 0.3$ & $3.84 \pm 0.2$ & 2.51 & n.s. & 5 & 7 \\
\hline & OFC & $2.71 \pm 0.2$ & $2.66 \pm 0.1$ & 0.05 & n.s. & 7 & 7 \\
\hline & AcbC & $1.62 \pm 0.2$ & $1.34 \pm 0.2$ & 0.98 & n.s. & 6 & 7 \\
\hline & $\mathrm{CPu}$ & $0.93 \pm 0.2$ & $0.87 \pm 0.1$ & 0.07 & n.s. & 7 & 6 \\
\hline & BNST & $0.76 \pm 0.1$ & $1.33 \pm 0.2$ & 11.13 & n.s. & 7 & 6 \\
\hline & $\mathrm{CeA}$ & $3.56 \pm 0.1$ & $4.97 \pm 0.3$ & 23.91 & $<0.01 * * *$ & 7 & 6 \\
\hline & $\mathrm{MeA}$ & $4.82 \pm 0.4$ & $6.15 \pm 0.3$ & 6.85 & n.s. & 7 & 6 \\
\hline & BLA & $2.96 \pm 0.2$ & $5.04 \pm 0.3$ & 34.72 & $<0.0 I^{* * *}$ & 7 & 7 \\
\hline & $\mathrm{MI}$ & $1.63 \pm 0.1$ & $|.5| \pm 0.1$ & 0.64 & n.s. & 5 & 7 \\
\hline & PVN & $6.56 \pm 0.5$ & $6.73 \pm 0.4$ & 0.06 & n.s. & 7 & 6 \\
\hline \multirow[t]{11}{*}{ Cacnald } & Cing & $7.89 \pm 0.5$ & $8.36 \pm 0.3$ & 0.70 & n.s. & 7 & 7 \\
\hline & PreL & $10.26 \pm 0.5$ & $9.68 \pm 0.2$ & 1.23 & n.s. & 6 & 7 \\
\hline & $\| \mathrm{L}$ & $10.65 \pm 0.2$ & $10.49 \pm 0.5$ & 0.10 & n.s. & 7 & 7 \\
\hline & OFC & $9.27 \pm 0.3$ & $8.81 \pm 0.2$ & 1.87 & n.s. & 7 & 7 \\
\hline & AcbC & $5.14 \pm 0.2$ & $5.23 \pm 0.1$ & 0.13 & n.s. & 7 & 7 \\
\hline & AcbS & $7.84 \pm 0.3$ & $7.85 \pm 0.2$ & 0.001 & n.s. & 7 & 7 \\
\hline & $\mathrm{CPu}$ & $3.87 \pm 0.3$ & $3.77 \pm 0.1$ & 0.11 & n.s. & 7 & 7 \\
\hline & BNST & $7.29 \pm 0.3$ & $6.76 \pm 0.2$ & 1.76 & n.s. & 7 & 7 \\
\hline & DG & $40.61 \pm 2.7$ & $39.67 \pm 3.3$ & 0.05 & n.s. & 7 & 6 \\
\hline & $\mathrm{MI}$ & $8.28 \pm 0.4$ & $8.21 \pm 0.2$ & 0.03 & n.s. & 6 & 7 \\
\hline & PVN & $14.73 \pm 0.6$ & $15.23 \pm 0.9$ & 0.24 & n.s. & 7 & 6 \\
\hline
\end{tabular}

Abbreviations: Alc. dep., alcohol dependent; Non-dep., nondependent; n.s., not significant.

Regions are as follows: cingulate cortex (Cing), prelimbic cortex (PreL), infralimbic region (IL), and orbitofrontal cortex (OFC), primary motor cortex (MI), nucleus accumbens (core $(A c b C)$ and shell $(A c b S)$ ), caudate putamen (CPu), extended amygdala (bed nucleus of the stria terminalis (BNST), central amygdala (CeA), medial amygdala (MeA), and basolateral amygdala (BLA)), hypothalamic paraventricular nucleus (PVN), and dorsal hippocampal formation (dentate gyrus (DG) and cornus ammon (CA) regions $\mathrm{CAI}$ and $\mathrm{CA} 3$ ).

Data were measured in $\mathrm{nCi} / \mathrm{g}$, shown as mean $\pm \mathrm{SEM}$. Statistical analysis was performed by region-wise one-way ANOVA followed by Bonferroni's correction; corrected

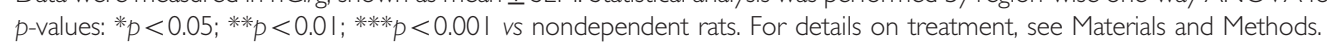

day 7 in the BLA $(p=$ n.s.), but a significant increase in alcohol-dependent rats on day $21(p<0.001)$. For absolute values, see Table 2 .

Furthermore, the expression of a panel of non-LTCC channels (ie, Cacna1A as P/Q-type channel, Cacna1B as N-type channel, Cacna1G as T-type channel) was analyzed by $\mathrm{qRT}-\mathrm{PCR}$ and showed a significant decrease in brain tissue of the hippocampus and amygdala region of 3-week abstinent rats (see Supplementary Tables S1 and S2).

\section{Increased Cav1.2 Current in Alcohol-Dependent Rats}

For functional validation of the increased Cav1.2 expression in alcohol-dependent rats, we conducted voltage-clamp recordings of L-type currents in acutely dissociated CA1 neurons (Figure 3 ), in which the majority $(\sim 80 \%)$ of LTCC currents are attributable to Cav1.2 (Hell et al, 1993). Although this allows for $20 \%$ of Cav1.3 contribution, the notably larger Cav1.2 expression in combination with the different activation thresholds of the two subtypes enabled 
a

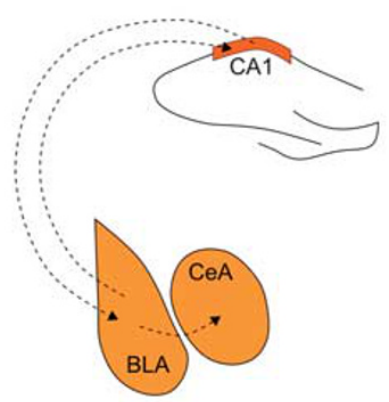

C

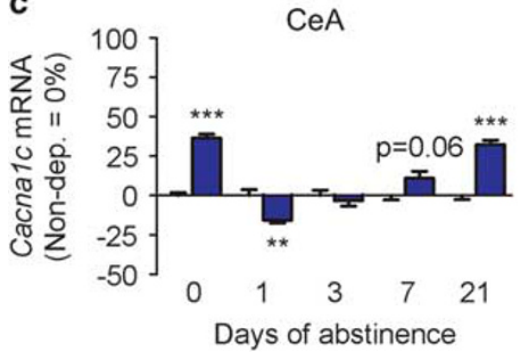

b
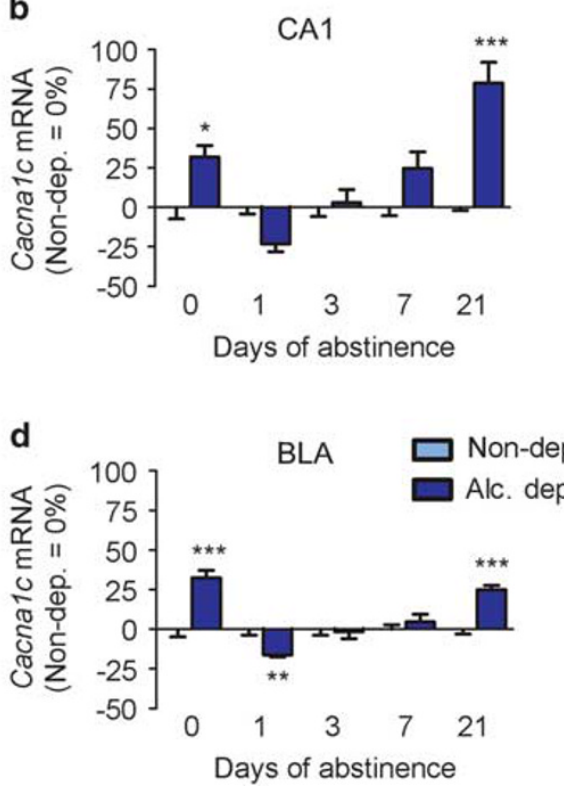

Figure 2 Cacna l c mRNA levels change over time during abstinence. (a) Schematic showing established anatomical connections of the dorsal hippocampal CAI region and the basolateral (BLA) and central (CeA) amygdala. Between CAI and BLA, there are connections in both directions. The BLA then relays the signal to the CeA (Ledoux, 2003; Kelley, 2004; Mandyam, 20 I3). (b-d) In situ hybridization shows similar dynamic regulation of Cacna I c mRNA during acute intoxication, withdrawal, and prolonged abstinence in the CAI (b), CeA (c), and BLA (d). Bar graphs show the percentage of regulation relative to control rats. Statistical analysis was performed by region-wise two-way ANOVA (time, treatment) followed by Bonferroni's correction, $n=6$-8/group (detailed in Table 2), p-values: ${ }^{*} p<0.05, * * p<0.01$, **** $p<0.00$ I. Alc., alcohol; Alc. dep., alcohol dependent; Non-dep., nondependent. Absolute values are listed in Table 2. For a detailed description of the in situ hybridization see Materials and Methods.

Table 2 Cacnalc mRNA Expression in Alcohol-Dependent and Nondependent Rats after 0, I, 3, 7, and 21 Days of Abstinence

\begin{tabular}{|c|c|c|c|c|c|}
\hline Region & $\begin{array}{c}\text { Days of } \\
\text { abstinence }\end{array}$ & $\begin{array}{l}\text { Non-dep. } \\
\text { (nCi/g) }\end{array}$ & $\begin{array}{l}\text { Alc. dep. } \\
\text { (nCi/g) }\end{array}$ & $\begin{array}{c}N \\
\text { Non-dep. }\end{array}$ & $\begin{array}{l}\text { N Alc. } \\
\text { dep. }\end{array}$ \\
\hline \multirow[t]{5}{*}{ CAI } & 0 & $11.28 \pm 1.2$ & $13.75 \pm 1.0$ & 8 & 6 \\
\hline & I & $13.69 \pm 0.7$ & $10.38 \pm 0.9$ & 8 & 8 \\
\hline & 3 & $10.66 \pm 0.5$ & $11.04 \pm 1.0$ & 6 & 7 \\
\hline & 7 & $10.63 \pm 0.6$ & $13.05 \pm 1.5$ & 8 & 8 \\
\hline & 21 & $7.54 \pm 0.1$ & $13.33 \pm 1.0$ & 7 & 8 \\
\hline \multirow[t]{5}{*}{$\mathrm{CeA}$} & 0 & $15.62 \pm 0.7$ & $21.45 \pm 0.5$ & 8 & 6 \\
\hline & I & $18.17 \pm 0.9$ & $13.70 \pm 0.4$ & 7 & 8 \\
\hline & 3 & $18.70 \pm 0.6$ & $16.78 \pm 0.7$ & 6 & 8 \\
\hline & 7 & $13.57 \pm 0.6$ & $16.7 \mid \pm 1.4$ & 8 & 7 \\
\hline & 21 & $12.44 \pm 0.4$ & $15.99 \pm 0.6$ & 7 & 8 \\
\hline \multirow[t]{5}{*}{ BLA } & 0 & $13.33 \pm 0.66$ & $17.65 \pm 0.3$ & 8 & 6 \\
\hline & I & $15.47 \pm 0.6$ & $12.88 \pm 0.3$ & 8 & 8 \\
\hline & 3 & $15.76 \pm 0.6$ & $15.47 \pm 0.8$ & 6 & 8 \\
\hline & 7 & $15.12 \pm 0.5$ & $16.73 \pm 1.6$ & 8 & 7 \\
\hline & 21 & $11.86 \pm 0.4$ & $13.76 \pm 0.6$ & 7 & 8 \\
\hline
\end{tabular}

Abbreviations: Alc. dep., alcohol dependent; Non-dep., nondependent; BLA, basolateral amygdala; CAI, dorsal hippocampal cornus ammon (CA) region; CeA, central amygdala.

Data were measured in $\mathrm{nCi} / \mathrm{g}$, shown as mean $\pm \mathrm{SEM}$. For details on treatment, see Materials and Methods.

the approximate distinction between Cav1.2 and Cav1.3 current. The dependence increased Cav1.2 expression in the hippocampus described earlier and the generally high expression in hippocampal subregions (Liebmann et al,
2008; Bernardi et al, 2014) also supported the choice of the CA1 region for electrophysiological measurements. Total whole-cell $\mathrm{Ca}^{2+}$ currents were recorded on step depolarizations of $200 \mathrm{~ms}$ from -60 to $+50 \mathrm{mV}$ with $-70 \mathrm{mV}$ holding potential (Vh). The currents started activating at the expected voltages $\left(>-40 \mathrm{mV}\right.$ in $2 \mathrm{mM} \mathrm{Ca}^{2+}$ ), had progressive fast activation with increasing voltages between -40 and $0 \mathrm{mV}$, and displayed the typical slowly inactivating time course because of the presence of $5 \mathrm{mM}$ EGTA inside the pipette (Figure 3a). Space- and dynamic-clamp control of the recordings was of high quality as shown in the Supplementary Figure S1 and discussed in the Supplementary Methods. The high-voltage activated calcium currents had a clear trend to be larger in alcohol-dependent animals, although the increase did not reach significance. Normalized $\mathrm{Ca}^{2+}$ channel conductances $\left(\mathrm{G}_{\text {norm }}(\mathrm{V})\right)$ were identical between CA1 neurons from control and alcohol-dependent animals, indicating no changes in the voltage dependence of calcium channel activation. The potential of half-maximal activation $\left(\mathrm{V}_{1 / 2}\right)(-15.2 \pm 0.9 \mathrm{mV}$ vs $-15.23 \pm 1 \mathrm{mV}$ for control and alcohol-dependent rats, respectively) and the maximal slope $(\mathrm{k})$ of $\mathrm{G}_{\text {norm }}(\mathrm{V})(6 \pm 0.4 \mathrm{mV}$ vs $5.3 \pm 0.4 \mathrm{mV}$ for control and alcohol-dependent rats, respectively) remained unchanged (Figure 3c), in good agreement with values typical for high-voltage activated calcium channels (Baldelli et al, 2000; Marcantoni et al, 2010; Mahapatra et al, 2011). As we were interested in the contribution of the L-type component to the total $\mathrm{Ca}^{2+}$ current, we consequently applied nifedipine $(3 \mu \mathrm{M})$ that is nearly saturating for Cav1.2 and Cav1.3 channels when applied on neurons held at $\mathrm{Vh}=-70 \mathrm{mV}$ (Mahapatra et al, 2011). At $0 \mathrm{mV}$, during which L-type currents reach their peak in $2 \mathrm{mM}$ extracellular 
a
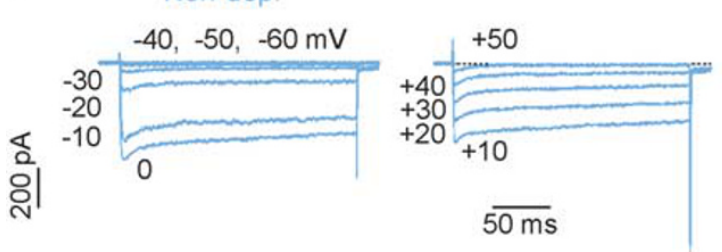

Alc. dep.

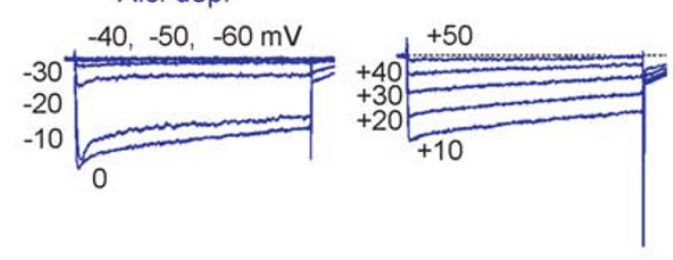

b
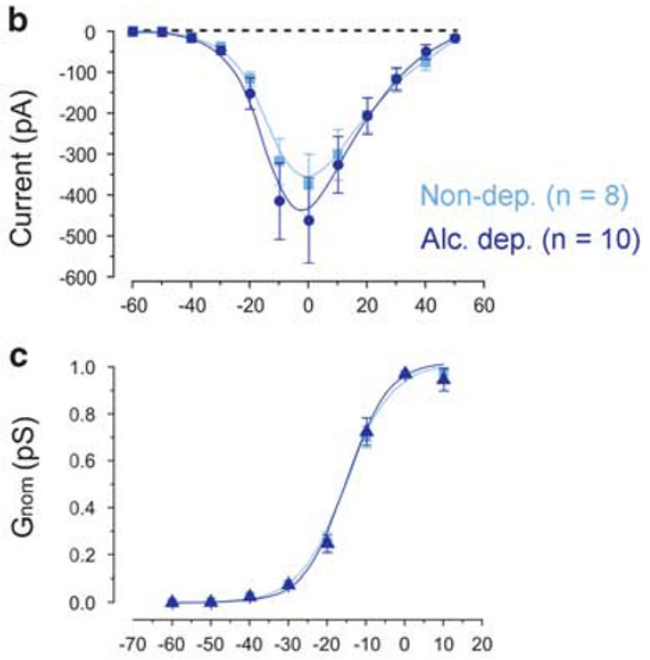

$\mathrm{mV}$
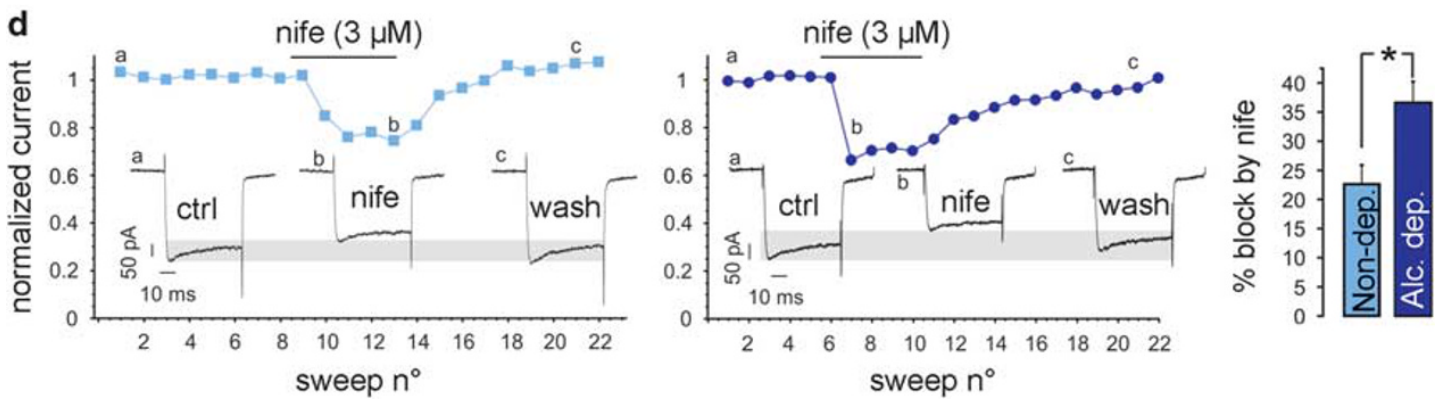

Figure 3 Alcohol exposure results in long-term upregulation of functional L-type $\mathrm{Ca}^{2+}$ channels. (a) Representative traces of whole-cell $\mathrm{Ca}^{2+}$ currents from -60 to $0 \mathrm{mV}$ (left) and from + 10 to $+50 \mathrm{mV}$ (right) recorded from neurons of alcohol-dependent (dark blue) and nondependent rats (light blue). Color code is valid for all panels. (b) Current-voltage relationship of calcium currents measured in $135 \mathrm{mM}$ extracellular TEA and $300 \mathrm{nM}$ TTX. (c) Normalized conductance, $\mathrm{G}=\mathrm{I} /\left(\mathrm{V}-\mathrm{E}_{\mathrm{Ca}}\right)$ of whole-cell calcium currents. $\mathrm{E}_{\mathrm{Ca}}$ is the reversal potential for calcium and set to $+50 \mathrm{mV}$. Data were fit by Boltzmann equations with $V_{1 / 2}=-15.2 \mathrm{mV}$ and $15.23 \mathrm{mV}$, and $\mathrm{k}=6.5 \mathrm{mV}$ and $5.3 \mathrm{mV}$ for neurons of control and alcohol-dependent rats (continuous curve). (d) Representative traces of calcium current block by the LTCC antagonist nifedipine ( $3 \mu \mathrm{M})$ and summarizing bar graph; ${ }^{*} p<0.05$, $t$-test. Alc., alcohol; Alc. dep., alcohol dependent; Non-dep., nondependent.

calcium, the nifedipine block was significantly larger in CA1 neurons from alcohol-dependent animals as compared with controls $(p<0.05$; Figure 3d). The L-type component contributed to $22.4 \pm 3.1 \%$ and $36.6 \pm 3.6 \%$ in control and alcohol-dependent animals, respectively $(p<0.05$; Figure $3 \mathrm{~d}$, right). The high degree of expression of Cav1.2 channels in CA1 neurons and the relatively high $\mathrm{V}_{1 / 2}$ derived from the Boltzmann fits of $G_{\text {norm }}(V)$ indicate that the contribution of Cav1.3 channels to the DHP-sensitive L-type currents is likely to be a small percentage $(<20 \%)$ of the alcohol effects on Cav1 channels. We thus conclude that alcohol exposure leads to an increase of functional L-type calcium channels with typical high-voltage activated channel features, as reported for Cav1.2. However, we should note that as the total calcium current amplitude was not significantly altered (Figure $3 b$ ), the possibility that a history of dependence may also act on non-L type calcium currents by reducing them cannot be excluded.

\section{Central Blockade of LTCCs Prevents Alcohol Seeking But Not Taking in Dependent Rats}

Verapamil, a nonselective LTCC antagonist, which is suitable for i.c.v. injections because of its water solubility (Jacob and De La Torre, 2009), was injected into the lateral ventricle of alcohol-dependent or nondependent rats immediately before a self-administration session $(120 \mu \mathrm{g} / 5 \mu \mathrm{l} \mathrm{aCSF})$. Two-way ANOVA showed a significant effect of the alcohol vapor exposure $(\mathrm{F}(1,23)=5.35, p<0.05)$, but no treatment or alcohol $\times$ treatment interaction effect. There was no difference between the individual groups according to the Newman-Keuls post hoc test (Figure 4). However, in the cue-induced reinstatement test, verapamil attenuated the seeking response in alcohol-dependent rats, whereas all other groups displayed a significant increase in active lever responses compared with extinction sessions (nondependent +aCSF: $\quad p<0.001$; nondependent+verapamil: $p<0.001$; alcohol dependent+aCSF: $p<0.001$ ). There was also a significant difference between verapamil-treated alcoholdependent and nondependent rats $(p<0.001)$ and between verapamil-treated and aCSF-treated alcohol-dependent rats $(p<0.001)$. In addition, aCSF-treated alcohol-dependent rats showed stronger reinstatement compared with aCSF-treated nondependent rats $(p<0.01$; Figure 4$)$.

\section{Lack of Cav1.2 in CaMKII $\alpha$-Positive Neurons Blocks Cue-Induced Reinstatement in Alcohol-Dependent Mice}

Because verapamil can act on Cav1.3, we validated the role of Cav1.2 for alcohol-seeking behavior using a novel 


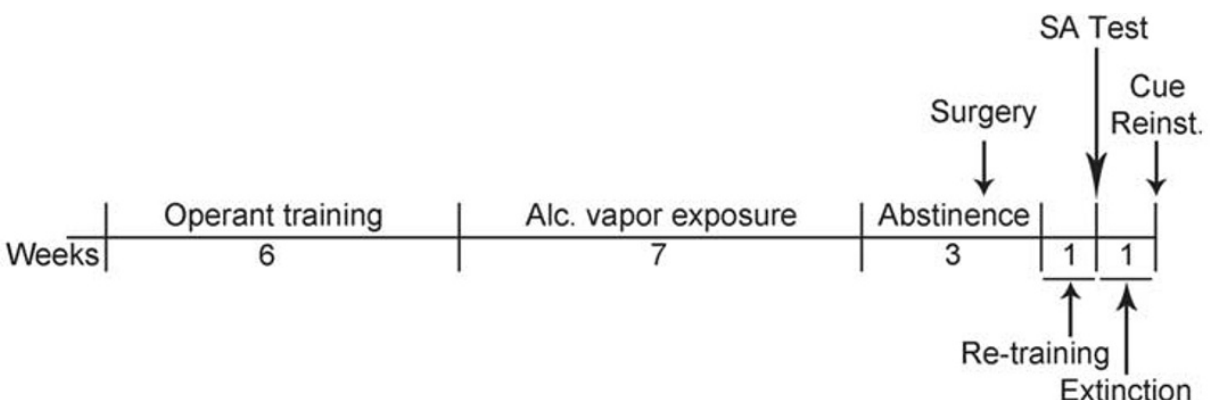

b

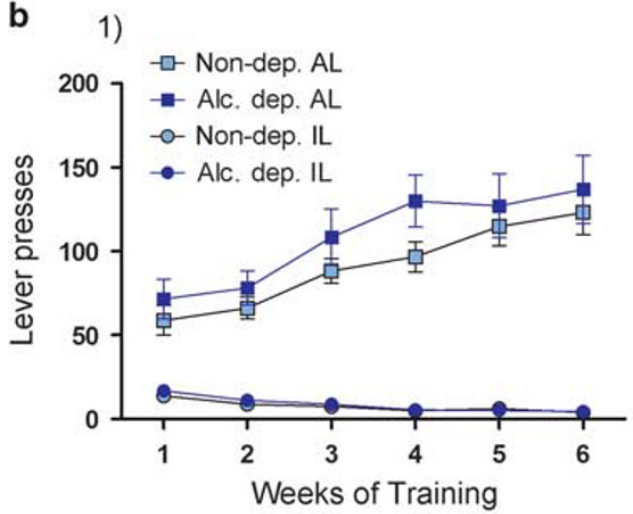

3)

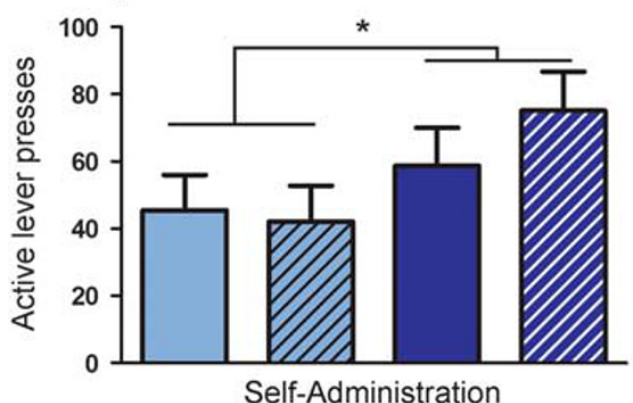

2)

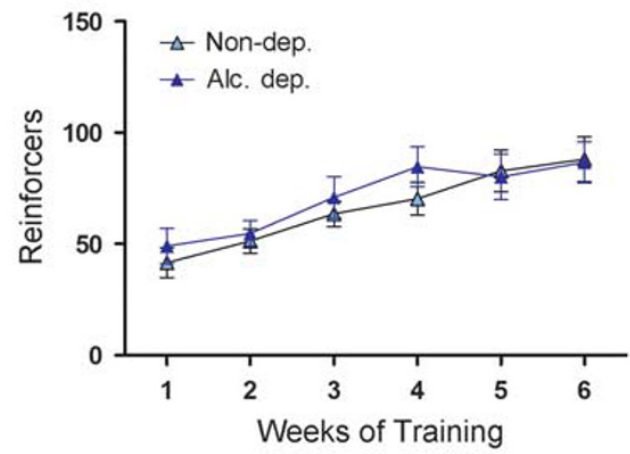

4)

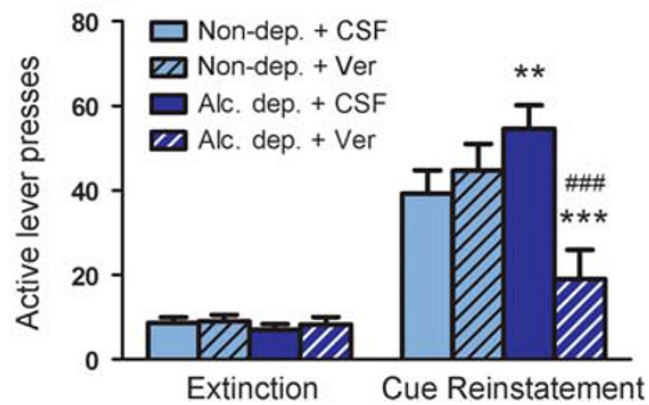

Figure 4 LTCC antagonist verapamil i.c.v. administration blocks cue-induced reinstatement of alcohol seeking in alcohol-dependent but not control rats, with no effect on alcohol self-administration. (a) Experimental outline: rats were trained to self-administer alcohol, and vapor or air exposed. During the following abstinence, guide cannulas for i.c.v. injections were implanted. After recovery rats were retrained, then tested for self-administration (SA) following i.c.v. injection of verapamil $(\mathrm{Ver}, 120 \mu \mathrm{g} / 5 \mu \mathrm{l})$ or vehicle $(\mathrm{aCSF}, 5 \mu \mathrm{l})$. This was followed by I week of extinction, after which cue-induced reinstatement was tested following i.c.v. injection of verapamil $(I 20 \mu \mathrm{g} / 5 \mu \mathrm{l})$ or aCSF $(5 \mu \mathrm{l})$. For details, see Materials and Methods. (b) (I) Graph shows lever presses during 6 weeks of self-administration training, with active lever (AL) presses steadily increasing and inactive lever presses (IL) at an expected low level. (2) As AL presses were followed by a $3 \mathrm{~s}$ timeout period during which additional lever presses did not result in alcohol delivery, rats received less reinforcers, as shown here. Neither AL and IL presses nor number of reinforcers differ between control and alcohol-dependent groups. (3) Self-administration following i.c.v. administration of verapamil or aCSF. Two-way ANOVA showed a significant overall effect on increased $\mathrm{AL}$ presses in dependent compared with nondependent rats $\left({ }^{*} p<0.05\right)$. Verapamil did not result in significant differences between groups. $N=7$ /group for non-dep. aCSF, non-dep. verapamil, and alc. dep. aCSF, and IL presses (not shown) were below I0 for all groups (range: 3.57-6.66 IL presses). $N=6 /$ group for alc. dep. verapamil. (4) Cue-induced reinstatement of alcohol-seeking following i.c.v. injection of verapamil was blocked in alcohol dependent rats. All other groups show significant reinstatement compared with extinction, and alcohol-dependent rats receiving aCSF show significantly higher reinstatement than control rats receiving aCSF. IL (not shown) were below I0 for all groups (range: I.42-2.27 IL presses in extinction, 3.5-6.8 IL presses in cue-induced reinstatement). Statistical analysis was performed by repeated measures ANOVA, followed by Newman-Keuls post hoc test, where appropriate, $p$-values: ${ }^{*} * p<0.01$, **** $p<0.00$ I alc.-dep. vs control; \#\# $p<0.00$ I verapamil vs CSF. N=8/group for non-dep. aCSF and alc. dep. aCSF, $N=6$ /group for non-dep. verapamil, and N=5/group for alc. dep. verapamil. Alc., alcohol; Alc. dep., alcohol dependent; Non-dep., nondependent.

conditional mutant mouse model in which a knockout of the gene is induced in forebrain neurons of adult mice. At 3 weeks after $\mathrm{KO}$ induction by tamoxifen, Cav1.2 ${ }^{\mathrm{KO}}$ mice and control littermates (Cav1.2 $2^{\mathrm{f} / \mathrm{fl}}$ ) were trained to selfadminister alcohol followed by induction of dependence as described together with the verification of the knockout in
Supplementary Information and Supplementary Figures S2 and $\mathrm{S} 3$.

Two-way ANOVA for Genotype $\times$ Treatment did not reveal significant overall effects on alcohol selfadministration (Genotype: $\mathrm{F}(1,27)=0.38, p=$ n.s.; Treatment: $\mathrm{F}(1,27)=0.15, p=$ n.s.). $A$ trend for a Genotype $\times$ 

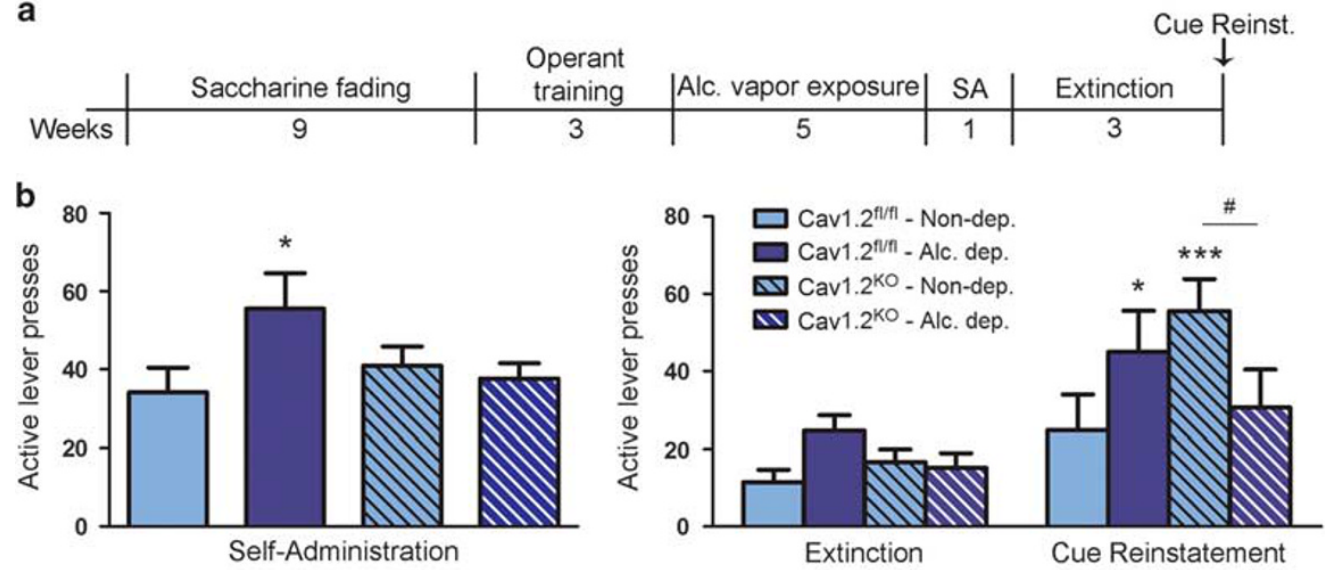

C

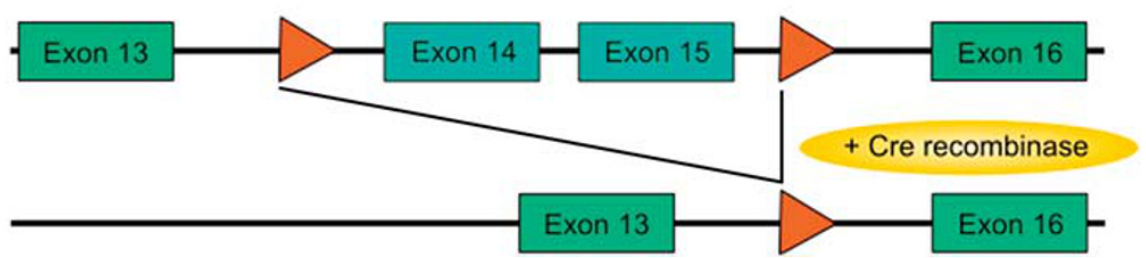

Figure 5 Conditional Cavl.2 knockout reduces alcohol self-administration and cue-induced reinstatement of alcohol seeking in alcohol dependence. (a) CaMKIl $\alpha$-Cavl.2 knockout (Cavl.2 ${ }^{\mathrm{KO}}$ ) and littermate Cavl. $2^{\mathrm{flfl}}$ control mice were trained to self-administer 10\% alcohol in operant chambers using a saccharine fading procedure followed by a training period in which the receipt of alcohol was associated with a light cue. Alcohol dependence was then induced through alcohol vapor exposure, followed by an additional week of alcohol self-administration sessions, 3 weeks of extinction, and finally by a cue-induced reinstatement test. (b, left) Alcohol dependence significantly increased active lever presses in Cavl.2 $2^{\mathrm{fl} / \mathrm{fl}}$ mice as compared with nondependent Cavl.2 $2^{\mathrm{fl} / \mathrm{fl}}$ mice. This increase was prevented in Cavl. $2^{\mathrm{KO}}$ mice; * $p<0.05$. (b, right) Alcohol-dependent Cavl. $2^{\mathrm{fl} / \mathrm{ll}}$ mice and nondependent Cavl. $2^{\mathrm{KO}}$ mice show significant reinstatement, * $p<0.05$, ${ }_{* * *}^{*} p<0.00 \mathrm{I}$ vs respective extinction group. Reinstatement behavior is attenuated in alcohol-dependent Cavl. $2^{\mathrm{KO}}$ mice, ${ }^{\#} p<0.05$, dependent vs nondependent Cavl. $2^{\mathrm{KO}}$ mice. $N=8 / \mathrm{group}$ for nondependent Cavl. $2^{\mathrm{flfl}}$ mice; $N=6 / \mathrm{group}$ for alc. dep. Cavl. $2^{\mathrm{fl} / \mathrm{l}}$ mice; $N=10 / \mathrm{group}$ for non-dependent Cavl. $2^{\mathrm{KO}}$ mice; and $N=7$ /group for alc. dep. Cavl. $2^{\mathrm{KO}}$ mice. IL presses are summarized in Supplementary Table S3. (c) Schematic representation of exons I 3 to I 6 of Cacnal c gene. LoxP sites are indicated by orange arrows. After tamoxifen treatment the Cre recombinase cuts out the DNA between the loxP sites in CaMKllo-expressing cells, thereby inducing a cell-specific Cavl.2 KO. Alc., alcohol; Alc. dep., alcohol dependent; Non-dep., nondependent.

Treatment interaction was seen $(\mathrm{F}(1,27)=4.07, p=0.05)$ that was because of a significant dependence-induced increase in active lever presses of control mice $(p<0.05$, dependent $v s$ nondependent Cav1.2 $2^{\mathrm{f} / \mathrm{fl}}$ mice) that was not observed in Cav1.2 ${ }^{\mathrm{KO}}$ mice (see Figure $5 \mathrm{a}$ ).

Cue-induced reinstatement of alcohol seeking was analyzed by repeated measures two-way ANOVA (Genotype $\times$ Treatment $\times$ Session, with Session consisting of extinction and cue-induced reinstatement). Significant main effects were found for Genotype $\times$ Treatment and Session (Genotype $\times$ Treatment: $F(1,27)=6.48, \quad p<0.05 ;$ Session: $\quad F$ $(1,27)=27.76, p<0.001)$. Importantly, alcohol-dependent Cav1.2 ${ }^{\mathrm{KO}}$ mice displayed a significant reduction of cueinduced reinstatement $(p<0.05$, nondependent $v s$ dependent Cav1. $2^{\mathrm{KO}}$ mice; $p<0.001$ extinction $v s$ reinstatement in nondependent Cav1. $2^{\mathrm{KO}}$ mice; Figure $5 \mathrm{~b}$ ), in line with the verapamil experiment in rats.

No changes in locomotor activity and anxiety-related behavior were detected as assessed in an Open Field test between naive Cav1.2 $\mathrm{KO}$ mice and their controls (Supplementary Figure S4).

\section{DISCUSSION}

Given the widespread clinical use of calcium antagonists that can influence the activity of LTCCs, the most salient message from the present study is that Cav1.2 is strongly upregulated in the alcoholic brain during abstinence and plays an important role in relapse behavior. Furthermore, we demonstrate the dynamic regulation of Cacnalc mRNA in the rat brain during abstinence from alcohol dependence. After 21 days of abstinence, Cacnalc mRNA was strongly increased, with no changes in Cacnald mRNA. This was accompanied by elevated Cav1.2 protein levels in the hippocampal CA1 subregion of alcohol-dependent rats. These findings were functionally validated by an increase in Cav1.2 currents in hippocampal CA1 neurons. Importantly, pharmacological blockade of central LTCCs prevented cue-induced alcohol seeking in dependent, but not control rats. Similarly, conditional knockout of Cav1.2 in forebrain neurons prevented a dependence-induced increase in alcohol-seeking responses. Together, our findings suggest an involvement of Cav1.2 in alcohol-seeking and relapse behavior, with substantial neuroadaptations taking place during abstinence.

To our knowledge, no studies have yet been published investigating the involvement of central LTCC subtypes on alcohol-related behavior. There have been efforts, however, to determine the individual roles of Cav1.2 and Cav1.3 in the abuse of other drugs such as nicotine (Bernardi et al, 2014), morphine (Shibasaki et al, 2011), and cocaine and amphetamine (Giordano et al, 2010; Schierberl et al, 2011, 2012). The findings in these studies are in line with our results on 
alcohol seeking, showing different contributions of the two subtypes during distinct stages following exposure to drugs of abuse. It appears that Cav1.2 is especially involved in the effects of long-term exposure to drugs of abuse and prolonged abstinence, as our current data, our study on nicotine sensitization (Bernardi et al, 2014), and the findings of Giordano et al (2006) on long-term amphetamine and cocaine exposure (Giordano et al, 2010), suggest.

To further establish the involvement of Cav1.2 in different stages of the development of alcohol dependence, we performed a time-course analysis of Cacnalc mRNA levels over time in the CA1, BLA, and CeA. Not only did these regions show the most pronounced effects after 21 days of abstinence, but they are also strongly interconnected (Ledoux, 2003; Kelley, 2004; Mandyam, 2013) and involved in the reconsolidation or retrieval of stimulus-associated memory (Otis et al, 2014; Shi et al, 2015). As such, these regions appear to play important roles in relapse to drug intake. All three regions showed a consistent pattern of Cacna1c mRNA increase during acute intoxication, followed by a decrease during early withdrawal (1 day of abstinence), and then again an increase during the following extended abstinence. These dynamic changes underline the possibility of differential involvement of this subunit over time. Cav1.2 may not be relevant during early withdrawal, as Cacnalc expression decreased immediately after the last alcohol vapor exposure, and rapidly normalized during the following days of abstinence. The strong increase after 21 days of abstinence indicates a role for Cav1.2 in long-term abstinence and possibly relapses. Similar fluctuations over time have recently been found in dopaminergic and glutamatergic systems during abstinence (Hermann et al, 2012; Hirth et al, 2016).

Using a Cav1.2-specific antibody, we were able to confirm the increased Cacnalc expression on the protein level. Because of the lack of subtype-specific pharmacological tools, we turned to electrophysiology for functional validation of our expression findings. Patch-clamp recordings from isolated neurons provide sufficient sensitivity and specificity to distinguish Cav1.2 from Cav1.3-mediated currents. Cav1.2 channels open at membrane potentials of about $-30 \mathrm{mV}$ and reach their half-maximal activation point at $-5 \mathrm{mV}$, whereas Cav1.3 has been shown to open at a much lower membrane potential (approximately $-55 \mathrm{mV}$ ), with a half-maximal activation point at $-30 \mathrm{mV}$ (Lipscombe, 2002). We measured Cav1.2/Cav1.3 currents in the CA1 region of the hippocampus in alcohol-dependent and control rats, as we found a strong increase of Cacnalc mRNA in this region after 21 days of abstinence. The CA1 region of adult rats also express high densities of Cav1.2 channels (Hell et al, 1993; Clark et al, 2003), and possess four times as much Cacnalc mRNA compared with Cacnald (Nunez-Santana et al, 2014). This suggests that despite nifedipine being a nonselective Cav1 channel blocker, most of the measured L-type currents in neurons of control and alcohol-dependent rats are mainly carried by Cav1.2. This is supported by the $G_{\text {norm }}(V)$ curves (Figure 3c), in which the voltage dependence matches more the Cav1.2 than Cav1.3 activation range. Our electrophysiological data are in very good agreement with the findings on the mRNA and protein levels, as nifedipine has a stronger blocking effect on calcium currents in neurons of alcoholdependent than control rats. It is of course possible that nonLTCCs are also involved in the measured response, considering the limited selectivity of available LTCC blockers. Therefore, the possibility of a compensatory decrease of either Cav1.3 or non-LTCCs to achieve an unchanged overall current cannot be excluded. A previous study from N'gouemo and Morad (2003) has shown that both L- and P-type calcium channels are increased in the inferior colliculus of rats after alcohol withdrawal from 4 days of intragastric administration, indicating effects of alcohol on non-LTCCs. In this paradigm, Cav1.3 appears to be the most relevant channel (N'gouemo et al, 2015); however, the paradigm is very different from our model of alcohol dependence as well as the brain regions analyzed. Furthermore, there are reports depicting a role of nonLTCCs, that is, N-type (Newton et al, 2008; Newton and Messing, 2009) and T-type calcium channels (Carden et al, 2006; Nordskog et al, 2006), in alcohol-related behavior. Therefore, we analyzed the expression of P/Q-type, N-type, and T-type non-LTCCs in 3-week abstinent rats by qRTPCR. Unlike Cacna1c, mRNA levels of non-LTCCs were significantly decreased in the amygdala and hippocampus (see Supplementary Table S2), thus suggesting opposite regulation of Cav1.2 and non-LTCCs. The results may further explain the unchanged total calcium current observed in our dependent rats.

Pharmacological validation was provided in alcoholdependent and control rats trained to self-administer alcohol in an operant conditioning experiment. The nonspecific LTCC antagonist verapamil, which has previously been used to block LTCCs in alcohol-related (Rezvani et al, 1990; De Beun et al, 1996a) and other research (Zhu and Herbert, 1997; Blackburn-Munro et al, 2000), was injected into the lateral ventricle, thus inhibiting only central LTCCs. Central injection of verapamil had no effect on alcohol selfadministration in either group, but prevented cue-induced reinstatement of alcohol seeking only in alcohol-dependent rats. Previous studies have demonstrated a reduction of alcohol intake and preference by i.p. administration of verapamil in alcohol-preferring rat strains (Rezvani and Janowsky, 1990; Fadda et al, 1992; De Beun et al, 1996a). These differences could be explained by the peripheral effects of systemic verapamil administration. The dissociation of verapamil's action on alcohol self-administration and seeking provides additional assurance for the behavioral specificity of the treatment inasmuch as there is no general suppression of behavior.

The most encouraging finding in terms of treatment development is the fact that verapamil did not alter cueinduced reinstatement in control rats, whereas it completely blocked it in alcohol-dependent animals. We have noted above, based on the reviewed literature, that many compounds lack distinct effects on alcohol behaviors between alcohol-dependent and nondependent rats, or in other words, may not specifically target the excessive component of alcohol-responding characteristic of the development of dependence (for review, see Meinhardt and Sommer, 2015). To date, only a few neurochemical systems have been identified that are additionally recruited in the control of alcohol behaviors in alcohol-dependent animals in a 'between-systems' adaptation mode as proposed by Koob and Le Moal (2008). The best studied in this respect is the amygdala corticotropin-releasing hormone (CRH) system (Hansson et al, 2006, 2007; Sommer et al, 2008), but similar 
dependence-specific adaptations have been observed in other brain stress systems, such as dynorphin (Walker et al, 2011) and vasopressin (Edwards et al, 2012) systems. Whether or not Cav1.2 mediates the actions of these stress systems and provides a distinct pharmacological access point into peptide systems proven difficult to target directly warrants further investigation. Such a prospect would justify the development of LTCC ligands with brain-specific pharmacodynamic properties, such as those acting via Cav1.2.

As verapamil might also affect Cav1.3 channels, we used a conditional mutant mouse model to establish a specific role of Cav1.2 in alcohol dependence-related behaviors. Specifically, deletion of the Cacna1c gene in forebrain neurons attenuated alcohol seeking in alcohol-dependent mice. Together with our verapamil data from rats, these findings provide converging evidence for increased sensitivity of Cav1.2-mediated effects in alcohol dependence. Compared with the robust effects on seeking behavior in the reinstatement test, alcohol self-administration was only mildly affected in the mouse and rat experiments. Specifically, alcohol-dependent control mice showed a significant increase in self-administration compared with nondependent mice. This effect was not seen in alcohol-dependent Cav1.2 ${ }^{\mathrm{KO}}$ compared with nondependent Cav1.2 $2^{\mathrm{KO}}$ mice. In the rat experiment, verapamil, which acts both on Cav1.2 and Cav1.3 channel subtypes, had no effect on alcohol selfadministration. Given the differences in approach between the two experiments and the modest effect size in mice, we found it difficult to draw robust conclusions. Together, these data may suggest opposite actions of Cav1.2 and Cav1.3 on dependence-induced escalation of alcohol-taking behavior. Further studies are warranted to examine specifically the role of Cav1.3 on this behavior.

In addition to alcohol dependence, Cav1.2 has been implicated in other mental disorders. Genetic studies have consistently associated variation in the CACNA1C gene locus with risk for schizophrenia, bipolar disorder, major depression, and autism (Casamassima et al, 2010; Strohmaier et al, 2013; Berger and Bartsch, 2014; Erk et al, 2014). Considering that there is a strong comorbidity between alcohol and other mental disorders, it seems plausible that Cav1.2, rather than Cav1.3, should play a role in the relapse to alcohol drinking.

In conclusion, we provide consistent evidence for increased Cav1.2 function in protracted abstinence. This hyperfunction is associated with increased alcohol seeking. We suggest Cav1.2 to be a new target for relapse prevention. Efforts in medicinal chemistry to develop centrally acting LTCC compounds are required to further explore the utility of this target for the treatment of alcohol use disorders.

\section{FUNDING AND DISCLOSURE}

The authors declare no conflict of interest.

\section{ACKNOWLEDGMENTS}

We thank Elisabeth Röbel, Sabrina Koch, Merle Kochan, and Leonie Mehrke for their invaluable technical assistance. The study was supported by the German Federal Ministry of Education and Research (BMBF, e:Med program, FKZ: 01ZX1311A Spanagel et al, 2013, IntegraMent FKZ:
01ZX1314H, ERA-Net TRANSALC, FKZ 01EW1112), European Union's Horizon 2020 research and innovation program (668863, SyBil-AA), and Deutsche Forschungsgemeinschaft (DFG HA6102/1-1, DFG Center Grant (SFB1134)).

\section{AUTHOR CONTRIBUTIONS}

$\mathrm{ACH}, \mathrm{EC}, \mathrm{RS}$, and WHS were responsible for study design and procured study funding. SU, REB, NH, and LB performed the mRNA analysis and behavioral experiments. ND and JMD performed the western blots. DV, AM, and EC conducted the electrophysiological experiments. KS and DB provided the Cav1.2 ${ }^{\mathrm{fl} / \mathrm{fl}}$ mice and demonstrated the Cav1.2 knockout. PG and MAV performed the behavioral characterization of the Cav1.2 $\mathrm{KO}$ mice. $\mathrm{AB}$ was responsible for the operant behavior in mice. SU, AB, PG, MAV, REB, EC, JMD, and $\mathrm{ACH}$ analyzed data. RS, SU, EC, WHS, and ACH wrote the manuscript.

\section{REFERENCES}

Baldelli P, Forni PE, Carbone E (2000). BDNF, NT-3 and NGF induce distinct new $\mathrm{Ca} 2+$ channel synthesis in developing hippocampal neurons. Eur J Neurosci 12: 4017-4032.

Berger SM, Bartsch D (2014). The role of L-type voltage-gated calcium channels Cav1.2 and Cav1.3 in normal and pathological brain function. Cell Tissue Res 357: 463-476.

Bernardi RE, Uhrig S, Spanagel R, Hansson AC (2014). Transcriptional regulation of L-type calcium channel subtypes Cav1.2 and Cav1.3 by nicotine and their potential role in nicotine sensitization. Nicotine Tob Res 16: 774-785.

Bjork K, Hansson AC, Sommer WH (2010). Genetic variation and brain gene expression in rodent models of alcoholism implications for medication development. Int Rev Neurobiol 91: 129-171.

Blackburn-Munro G, Brown CH, Neumann ID, Landgraf R, Russell JA (2000). Verapamil prevents withdrawal excitation of oxytocin neurones in morphine-dependent rats. Neuropharmacology 39: 1596-1607.

Carden WB, Alexander GM, Friedman DP, Daunais JB, Grant KA, $\mathrm{Mu} \mathrm{J}$ et al (2006). Chronic ethanol drinking reduces native T-type calcium current in the thalamus of nonhuman primates. Brain Res 1089: 92-100.

Casamassima F, Hay AC, Benedetti A, Lattanzi L, Cassano GB, Perlis RH (2010). L-type calcium channels and psychiatric disorders: a brief review. Am J Med Genet B Neuropsychiatr Genet 153B: 1373-1390.

Clark NC, Nagano N, Kuenzi FM, Jarolimek W, Huber I, Walter D et al (2003). Neurological phenotype and synaptic function in mice lacking the CaV1.3 alpha subunit of neuronal L-type voltage-dependent Ca2+ channels. Neuroscience 120: 435-442.

Colombo G, Agabio R, Lobina C, Reali R, Melis F, Fadda F et al (1995). Effects of the calcium channel antagonist darodipine on ethanol withdrawal in rats. Alcohol Alcohol 30: 125-131.

De Beun R, Schneider R, Klein A, Lohmann A, De Vry J (1996a). Effects of nimodipine and other calcium channel antagonists in alcohol-preferring AA rats. Alcohol 13: 263-271.

De Beun R, Schneider R, Klein A, Lohmann A, Schreiber R, De Vry J (1996b). The calcium channel agonist BAY k 8644 reduces ethanol intake and preference in alcohol-preferring AA rats. Psychopharmacology (Berl) 127: 302-310.

Edwards S, Guerrero M, Ghoneim OM, Roberts E, Koob GF (2012). Evidence that vasopressin V1b receptors mediate the transition to excessive drinking in ethanol-dependent rats. Addict Biol 17: $76-85$. 
Erk S, Meyer-Lindenberg A, Schmierer P, Mohnke S, Grimm O, Garbusow $\mathrm{M}$ et al (2014). Hippocampal and frontolimbic function as intermediate phenotype for psychosis: evidence from healthy relatives and a common risk variant in CACNA1C. Biol Psychiatry 76: 466-475.

Fadda F, Garau B, Colombo G, Gessa GL (1992). Isradipine and other calcium channel antagonists attenuate ethanol consumption in ethanol-preferring rats. Alcohol Clin Exp Res 16: 449-452.

Gardell LR, Reid LD, Boedeker KL, Liakos TM, Hubbell CL (1997). Isradipine and naltrexone in combination with isradipine interact with a period of abstinence to reduce rats' intakes of an alcoholic beverage. Alcohol Clin Exp Res 21: 1592-1598.

Gardell LR, Reid ML, Cavallero CA, Burgess SE, Wallace RF, Hubbell CL et al (1999). Amlodipine, a calcium channel inhibitor, and cocaine and ethanol's reinforcing effects. Pharmacol Biochem Behav 64: 567-572.

Giordano TP, Satpute SS, Striessnig J, Kosofsky BE, Rajadhyaksha AM (2006). Up-regulation of dopamine $\mathrm{D}(2) \mathrm{L}$ mRNA levels in the ventral tegmental area and dorsal striatum of amphetaminesensitized C57BL/6 mice: role of $\mathrm{Ca}(\mathrm{v}) 1.3 \mathrm{~L}$-type $\mathrm{Ca}(2+)$ channels. J Neurochemistry 99: 1197-1206.

Giordano TP, Tropea TF, Satpute SS, Sinnegger-Brauns MJ, Striessnig J, Kosofsky BE et al (2010). Molecular switch from L-type Ca v 1.3 to $\mathrm{Ca}$ v 1.2 Ca2+ channel signaling underlies longterm psychostimulant-induced behavioral and molecular plasticity. J Neurosci 30: 17051-17062.

Hansson AC, Cippitelli A, Sommer WH, Ciccocioppo R, Heilig M (2007). Region-specific down-regulation of Crhr1 gene expression in alcohol-preferring msP rats following ad lib access to alcohol. Addict Biol 12: 30-34.

Hansson AC, Cippitelli A, Sommer WH, Fedeli A, Bjork K, Soverchia $\mathrm{L}$ et al (2006). Variation at the rat Crhr1 locus and sensitivity to relapse into alcohol seeking induced by environmental stress. Proc Natl Acad Sci USA 103: 15236-15241.

Hansson AC, Nixon K, Rimondini R, Damadzic R, Sommer WH, Eskay $\mathrm{R}$ et al (2010). Long-term suppression of forebrain neurogenesis and loss of neuronal progenitor cells following prolonged alcohol dependence in rats. Int J Neuropsychopharmacol 13: 583-593.

Heilig M, Egli M, Crabbe JC, Becker HC (2010). Acute withdrawal, protracted abstinence and negative affect in alcoholism: are they linked? Addict Biol 15: 169-184.

Hell JW, Westenbroek RE, Warner C, Ahlijanian MK, Prystay W, Gilbert MM et al (1993). Identification and differential subcellular localization of the neuronal class C and class D L-type calcium channel alpha 1 subunits. J Cell Biol 123: 949-962.

Hermann D, Weber-Fahr W, Sartorius A, Hoerst M, Frischknecht U, Tunc-Skarka N et al (2012). Translational magnetic resonance spectroscopy reveals excessive central glutamate levels during alcohol withdrawal in humans and rats. Biol Psychiatry 71: 1015-1021.

Hirth N, Meinhardt MW, Noori HR, Hsalgado H, Torres-Ramirez O, Uhrig $S$ et al (2016). Convergent evidence from alcohol dependent humans and rats for a hyperdopaminergic state in protracted abstinence. Proc Natl Acad Sci USA 113: 3024-3029.

Jacob SW, De La Torre JC (2009). Pharmacology of dimethyl sulfoxide in cardiac and CNS damage. Pharmacol Rep 61: 225-235.

Kelley AE (2004). Memory and addiction: shared neural circuitry and molecular mechanisms. Neuron 44: 161-179.

Koob GF, Le Moal M (2008). Addiction and the brain antireward system. Annu Rev Psychol 59: 29-53.

Ledoux J (2003). The emotional brain, fear, and the amygdala. Cell Mol Neurobiol 23: 727-738.

Liebmann L, Karst H, Sidiropoulou K, Van Gemert N, Meijer OC, Poirazi P et al (2008). Differential effects of corticosterone on the slow afterhyperpolarization in the basolateral amygdala and CA1 region: possible role of calcium channel subunits. J Neurophysiol 99: $958-968$

Lipscombe D (2002). L-type calcium channels: highs and new lows. Circ Res 90: 933-935.

Littleton JM, Little HJ, Whittington MA (1990). Effects of dihydropyridine calcium channel antagonists in ethanol withdrawal; doses required, stereospecificity and actions of Bay $\mathrm{K}$ 8644. Psychopharmacology (Berl) 100: 387-392.

Mahapatra S, Marcantoni A, Vandael DH, Striessnig J, Carbone E (2011). Are $\mathrm{Ca}(\mathrm{v}) 1.3$ pacemaker channels in chromaffin cells? Possible bias from resting cell conditions and DHP blockers usage. Channels (Austin) 5: 219-224.

Mandyam CD (2013). The interplay between the hippocampus and amygdala in regulating aberrant hippocampal neurogenesis during protracted abstinence from alcohol dependence. Front Psychiatry 4: 61.

Marcantoni A, Vandael DH, Mahapatra S, Carabelli V, Sinnegger-Brauns MJ, Striessnig J et al (2010). Loss of Cav1.3 channels reveals the critical role of L-type and BK channel coupling in pacemaking mouse adrenal chromaffin cells. $J$ Neurosci 30: 491-504.

Meinhardt MW, Hansson AC, Perreau-Lenz S, Bauder-Wenz C, Stahlin O, Heilig M et al (2013). Rescue of infralimbic mGluR2 deficit restores control over drug-seeking behavior in alcohol dependence. J Neurosci 33: 2794-2806.

Meinhardt MW, Sommer WH (2015). Postdependent state in rats as a model for medication development in alcoholism. Addict Biol 20: $1-21$.

N'gouemo P, Akinfiresoye LR, Allard JS, Lovinger DM (2015). Alcohol withdrawal-induced seizure susceptibility is associated with an upregulation of $\mathrm{CaV} 1.3$ channels in the rat inferior colliculus. Int J Neuropsychopharmacol 18: pyu123.

N'gouemo P, Morad M (2003). Ethanol withdrawal seizure susceptibility is associated with upregulation of L- and P-type $\mathrm{Ca} 2+$ channel currents in rat inferior colliculus neurons. Neuropharmacology 45: 429-437.

Newton PM, Messing RO (2009). The N-type calcium channel is a novel target for treating alcohol use disorders. Channels (Austin) 3: 77-81.

Newton PM, Zeng L, Wang V, Connolly J, Wallace MJ, Kim C et al (2008). A blocker of $\mathrm{N}$ - and T-type voltage-gated calcium channels attenuates ethanol-induced intoxication, place preference, selfadministration, and reinstatement. J Neurosci 28: 11712-11719.

Noori HR, Spanagel R, Hansson AC (2012). Neurocircuitry for modeling drug effects. Addict Biol 17: 827-864.

Nordskog BK, Hammarback JA, Godwin DW (2006). Diurnal gene expression patterns of T-type calcium channels and their modulation by ethanol. Neuroscience 141: 1365-1373.

Nunez-Santana FL, Oh MM, Antion MD, Lee A, Hell JW, Disterhoft JF (2014). Surface L-type Ca2+ channel expression levels are increased in aged hippocampus. Aging Cell 13: 111-120.

Otis JM, Fitzgerald MK, Mueller D (2014). Inhibition of hippocampal beta-adrenergic receptors impairs retrieval but not reconsolidation of cocaine-associated memory and prevents subsequent reinstatement. Neuropsychopharmacology 39: 303-310.

Pucilowski O, Krzascik P, Trzaskowska E, Kostowski W (1989). Different effect of diltiazem and nifedipine on some central actions of ethanol in the rat. Alcohol 6: 165-168.

Rashidy-Pour A, Vafaei AA, Taherian AA, Miladi-Gorji H, Sadeghi H, Fathollahi Y et al (2009). Verapamil enhances acute stress or glucocorticoid-induced deficits in retrieval of long-term memory in rats. Behav Brain Res 203: 76-80.

Rezvani AH, Janowsky DS (1990). Decreased alcohol consumption by verapamil in alcohol preferring rats. Prog Neuropsychopharmacol Biol Psychiatry 14: 623-631.

Rezvani AH, Mack CM, De Lacy PA, Janowsky DS (1990). Verapamil effects on physiological and behavioral responses to ethanol in the rat. Alcohol Alcohol 25: 51-58. 
Rimondini R, Arlinde C, Sommer W, Heilig M (2002). Long-lasting increase in voluntary ethanol consumption and transcriptional regulation in the rat brain after intermittent exposure to alcohol. FASEB J 16: 27-35.

Schierberl K, Giordano T, Satpute S, Hao J, Kaur G, Hofmann F et al (2012). Cav 1.3L-type Ca (2+) channels mediate long-term adaptation in dopamine D2L-mediated GluA1 trafficking in the dorsal striatum following cocaine exposure. Channels (Austin) 6: 11-17.

Schierberl K, Hao J, Tropea TF, Ra S, Giordano TP, Xu Q et al (2011). Cav1.2L-type $\mathrm{Ca}(2)(+)$ channels mediate cocaine-induced GluA1 trafficking in the nucleus accumbens, a long-term adaptation dependent on ventral tegmental area $\mathrm{Ca}(\mathrm{v}) 1.3$ channels. J Neurosci 31: 13562-13575.

Shi HS, Luo YX, Yin X, Wu HH, Xue G, Geng XH et al (2015). Reconsolidation of a cocaine associated memory requires DNA methyltransferase activity in the basolateral amygdala. Sci Rep 5: 13327.

Shibasaki M, Kurokawa K, Mizuno K, Ohkuma S (2011). Upregulation of $\mathrm{Ca}(\mathrm{v}) 1.2$ subunit via facilitating trafficking induced by Vps34 on morphine-induced place preference in mice. Eur J Pharmacol 651: 137-145.

Sommer WH, Rimondini R, Hansson AC, Hipskind PA, Gehlert DR, Barr CS et al (2008). Upregulation of voluntary alcohol intake, behavioral sensitivity to stress, and amygdala crhr1 expression following a history of dependence. Biol Psychiatry 63: 139-145.

Spanagel R (2009). Alcoholism: a systems approach from molecular physiology to addictive behavior. Physiol Rev 89: 649-705.

Spanagel R, Durstewitz D, Hansson A, Heinz A, Kiefer F, Kohr G et al (2013). A systems medicine research approach for studying alcohol addiction. Addict Biol 18: 883-896.

Strohmaier J, Amelang M, Hothorn LA, Witt SH, Nieratschker V, Gerhard D et al (2013). The psychiatric vulnerability gene CACNA1C and its sex-specific relationship with personality traits, resilience factors and depressive symptoms in the general population. Mol Psychiatry 18: 607-613.

Walker BM, Zorrilla EP, Koob GF (2011). Systemic kappa-opioid receptor antagonism by nor-binaltorphimine reduces dependence-induced excessive alcohol self-administration in rats. Addict Biol 16: 116-119.

Waltereit R, Mannhardt S, Nescholta S, Maser-Gluth C, Bartsch D (2008). Selective and protracted effect of nifedipine on fear memory extinction correlates with induced stress response. Learn Mem 15: 348-356.

World Health Organization (2014). Global status report on alcohol and health. www.who.int/substance_abuse/publications/alcohol_ 2014/en/.

Zhu B, Herbert J (1997). Calcium channels mediate angiotensin IIinduced drinking behaviour and c-fos expression in the brain. Brain Res 778: 206-214.

Supplementary Information accompanies the paper on the Neuropsychopharmacology website (http://www.nature.com/npp) 